Research article

\title{
Three-dimensional lateral pterygoid muscle volume: MRI analyses with insertion patterns correlation
}

\author{
Gabriela Sobral de Figueiredo Melke ${ }^{\mathrm{a}}$, André Luiz Ferreira Costa ${ }^{\mathrm{a}, *}$, \\ Sérgio Lúcio Pereira de Castro Lopes ${ }^{\mathrm{b}}$, Acacio Fuziy ${ }^{\mathrm{a}}$, Rívea Inês Ferreira-Santos ${ }^{\mathrm{c}}$ \\ a Department of Orthodontics, University of São Paulo City, São Paulo, São Paulo, Brazil \\ b Department of Diagnosis and Surgery, São José dos Campos Dental School, São Paulo State University, São José dos Campos, São Paulo, Brazil \\ ${ }^{c}$ Department of Radiology, Universidade Paulista, Campinas, SP, Brazil
}

\section{A R T I C L E I N F O}

\section{Article history:}

Received 11 March 2016

Received in revised form 25 April 2016

Accepted 13 May 2016

\section{Keywords:}

Temporomandibular joint

Muscle, Skeletal

MRI, Diagnostic imaging

\begin{abstract}
A B S T R A C T
We evaluated lateral pterygoid muscle volume in closed and open mouth positions in association with anterior disc displacement, effusion and abnormal articular disc shape from three-dimensional reformations of MRI. A total of 24 MRI of a sample (15 females, 9 males) aged 19-64 years (37.2 years \pm 11.4 ) were assessed. Segmentation and volumetric assessment of the total, upper and lower heads of the lateral pterygoid muscle were performed using free software. The upper head of the lateral pterygoid muscle had a smaller volume than the lower head at both sides, in the closed- and open-mouth positions. In the open-mouth position, individuals with a subdivided upper head, where one component was inserted in the articular disc and another in the mandibular head, displayed a significantly larger volume of the upper head compared to individuals who had a single attachment to the articular disc $(p=0.0130)$. The lateral pterygoid muscle has different volumes in the closed- and open-mouth positions. Gender affected muscle volume, specifically the upper head component. Insertion type in the upper head also seemed to affect muscle volume.
\end{abstract}

(c) 2016 Elsevier GmbH. All rights reserved.

\section{Introduction}

During the past decades, an increasing number of studies have focused on the temporomandibular joint (TMJ) because of its complex anatomy and relatively high susceptibility to pathological alterations (Costa et al., 2008a, 2008b, 2014; Dworkin, 2010; Dworkin and LeResche, 1992; Lopes et al., 2012). Such alterations often result in symptoms that characterize a temporomandibular disorder (TMD). The anterior articular disc displacement represents the most prevalent TMD (Costa et al., 2008a). Diagnosis in these cases requires precise location of the disc, usually via magnetic resonance imaging (MRI) (Costa et al., 2008b; Tomas et al., 2006).

This imaging technique also allows for the assessment of muscles of mastication and their possible involvement in TMD (Balcioglu et al., 2009; Barriere et al., 2009; D’Ippolito et al., 2010; Farrugia et al., 2007; Goto et al., 2002; Imanimoghaddam et al., 2013; Lamey et al., 2001; Mazza et al., 2009; Ng et al., 2009; Omami

\footnotetext{
* Corresponding author at: Department of Orthodontics, UNICID, Rua Cesário Galeno 448, Bloco A. Tatuapé, 03071-000 São Paulo, Brazil. Tel.: +55 112178 1294; fax: +55112178 1355 .

E-mail address: alfcosta@gmail.com (A.L.F. Costa).
}

and Lurie, 2012; Schellhas, 1989; Taskaya-Yilmaz et al., 2005). The lateral pterygoid muscle (LPM) represents one of the most important muscles in the physiology of mastication, and, inserted in the TMJ, it acts in mandibular opening, lateral movement and protrusion (D'Ippolito et al., 2010; Omami and Lurie, 2012). The LPM is a symmetric paired muscle, located in the interior of the infratemporal fossa, formed by an upper head (connected to the TMJ articular disc) and a lower head (Imanimoghaddam et al., 2013; Mazza et al., 2009; Omami and Lurie, 2012). Articular disc displacements without reduction or effusion may result from alterations in the physiology of muscles of mastication (Costa et al., 2008a; D'Ippolito et al., 2010).

Previous studies report increased LPM volume occurring in parallel to (and on the same side as) unilateral mastication (Goto et al., 2002), and greater thickness of this muscle is associated with anterior disc displacement and articular hypermobility (Benington et al., 1999). However, some authors suggest that anterior articular disc displacement without reduction may correlate with atrophy of the upper head of the lateral pterygoid muscle (Balcioglu et al., 2009).

In this study, we used MRI to evaluate associations between lateral pterygoid volume - total muscle, upper and lower head volumes - in open- and closed-mouth positions with TMDs, including 
Table 1

Sample characteristics: gender, age and TMJ pain.

\begin{tabular}{|c|c|c|c|c|c|c|}
\hline \multirow[t]{3}{*}{ Characteristics } & \multicolumn{6}{|c|}{ Gender } \\
\hline & \multicolumn{2}{|c|}{ Female } & \multicolumn{2}{|c|}{ Male } & \multicolumn{2}{|c|}{ Total } \\
\hline & $n$ & $\%$ & $n$ & $\%$ & $n$ & $\%$ \\
\hline \multicolumn{7}{|l|}{ Age } \\
\hline$\leq 39$ & 10 & 66.7 & 4 & 44.4 & 14 & 58.3 \\
\hline$\geq 40$ & 5 & 33.3 & 5 & 55.6 & 10 & 41.7 \\
\hline \multicolumn{7}{|l|}{ Pain } \\
\hline No & 10 & 66.7 & 5 & 55.6 & 15 & 62.5 \\
\hline Yes & 5 & 33.3 & 4 & 44.4 & 9 & 37.5 \\
\hline Total & 15 & 100.0 & 9 & 100.0 & 24 & 100.0 \\
\hline
\end{tabular}

anterior articular disc displacements, effusion, and morphological alterations in the articular disc.

\section{Materials and methods}

\subsection{Sample selection}

The images were originally taken as part of previous research. After approval by the UNICID Research Ethics Committee (protocol number 13350813.1.0000.0064), MRI from 24 patients ( 15 women and 9 men) between 19 and 64 years of age (37.2 years \pm 11.4 ) were selected for analysis, from an initial sample derived from 57 individuals. Discarded images were not clear enough, as per the exclusion criteria discussed below. Five of the 24 patients were diagnosed with anterior articular disc dislocation and effusion, 6 had only anterior articular disc dislocation, 3 had only effusion, and the remaining 10 were negative for both TMDs. Based on the physical exams performed prior to this study, 33.3\% of women and $44.4 \%$ of men reported TMJ pain (Table 1 ).

Two dentomaxillofacial radiologists evaluated the MRIs in the open- and closed-mouth positions to describe disc morphology and diagnose dislocation and/or effusion. The position of articular discs was defined based on previously established criteria using parasagittal images (Lopes et al., 2012). Discs were considered normally positioned when, in a closed mouth, their posterior band aligned with the superior part of the mandible head, an anterior articular disc displacement was defined by the anterior positioning of the posterior band of the disc in relation to the mandible head. In MRIs of open mouths, the anterior dislocations were grouped as "with reduction" - when the posterior band of the disc realigned with the mandible head - or "without reduction" - when the disc maintained an anterior position in relation to the articular tubercle (Taskaya-Yilmaz et al., 2005). Articular effusion was identified as a hyperintense signal in the superior and/or inferior articular spaces
(Costa et al., 2008a). Articular disc morphology was analyzed in the open- and closed-mouth positions and classified as normal biconcave or abnormal with altered morphology (Fig. 1) (Amaral Rde et al., 2013).

The MRI files were selected according to the following inclusion criteria (Costa et al., 2008b): all patients should have received a positive or negative diagnosis of anterior articular disc displacement, through MRI analysis. However, patients could not have concurrent conditions such as rheumatoid arthritis, rheumatic psoriasis, and severe myasthenia (Schellhas, 1989). Exclusion criteria included: impaired visualization of the LPM; impaired visualization of details; images with low sharpness resulting from patient movements during scanning; signs of previous patient trauma; signs of other systemic conditions that might alter the TMJ and muscles of mastication; presence of metallic prosthetics and accessories and any history of TMJ-related therapy.

\subsection{Image acquisition data}

All patients were submitted to bilateral MRI of the TMJ in Signa $1.5 \mathrm{~T}$ equipment (GE Medical systems, Milwaukee, WI, USA) with $8.5 \mathrm{~cm}$ surface coils. Initially, 24 axial T1-weighted slices were acquired in spin echo (SE) sequence (repetition time TR $=1400 \mathrm{~ms}$, echo time $\mathrm{TE}=1.6 \mathrm{~ms}$, slice thickness $\mathrm{ST}=5.0 \mathrm{~mm}$ field of vision FOV of $18.0 \mathrm{~cm} \times 18.0 \mathrm{~cm}$, in a $256 \times 256$ matrix). Among these slices, we selected the one allowing for better visualization of the mandible along its long axis. Based on this slice, we then established the orientation of the parasagittal planes. In this study, specifically, we utilized parasagittal proton-density images of the closed-mouth and open-mouth positions in SE sequence $(\mathrm{TR}=1200 \mathrm{~ms}, \mathrm{TE}=13.7 \mathrm{~ms}, \mathrm{ST}=3.0 \mathrm{~mm}, \mathrm{FOV}=150 \mathrm{~cm} \times 150 \mathrm{~mm}$, image matrix $=512 \times 512$, excitation number $N E X=2$, radiofrequency 4 and excitation angle of the radiofrequency pulse/flip angle $=20^{\circ}$ ). All parasagittal slices in the lateromedial direction were analyzed. To evaluate pathological states, including effusion, we utilized oblique sagittal T2-weighted images $(\mathrm{TR}=1500.0 \mathrm{~ms}$, $\mathrm{TE}=100.2 \mathrm{~ms}, \mathrm{ST}=3.0 \mathrm{~mm}, \mathrm{FOV}=15 \mathrm{~cm} \times 15 \mathrm{~cm}$, and $512 \times 512$ matrix) with central cuts in three stages (closed-mouth, half-open mouth and open-mouth).

\subsection{Image segmentation and volumetry}

Selected MRI files were number-coded to protect patient identities and converted from DICOM (Digital Imaging and Communications in Medicine) to the ANALYZE format utilizing the MRICro software (www.mricro.com). After format conversion, the ITKSNAP® software (http://www.itksnap.org/download/snap/) was utilized to segment the entire right and left lateral pterygoid

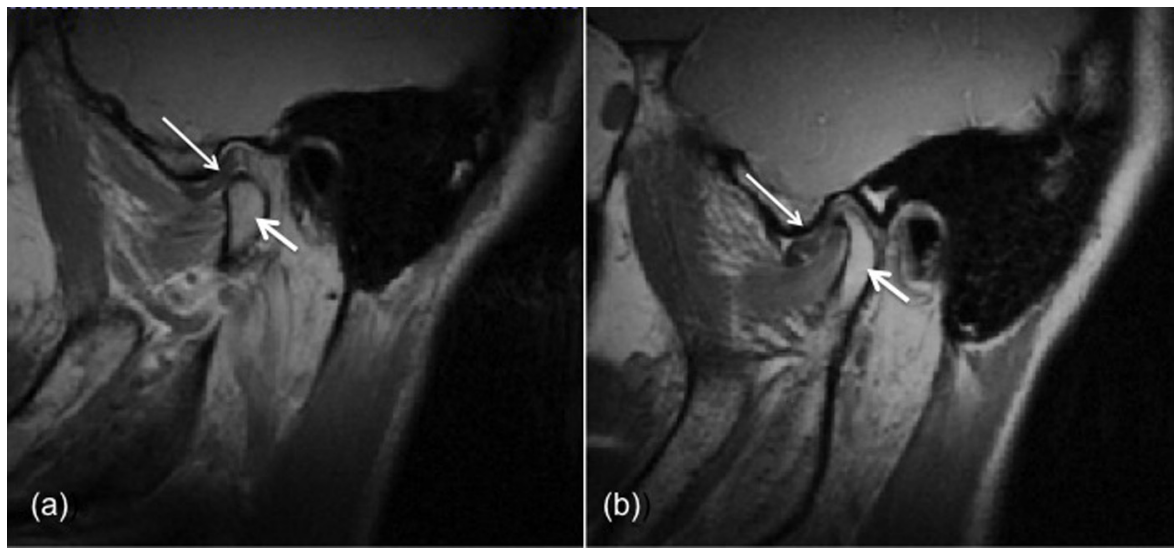

Fig. 1. Articular disc morphology in the closed-mouth position: (a) normal and (b) altered. Long arrow: articular disc; short arrow: condyle. 

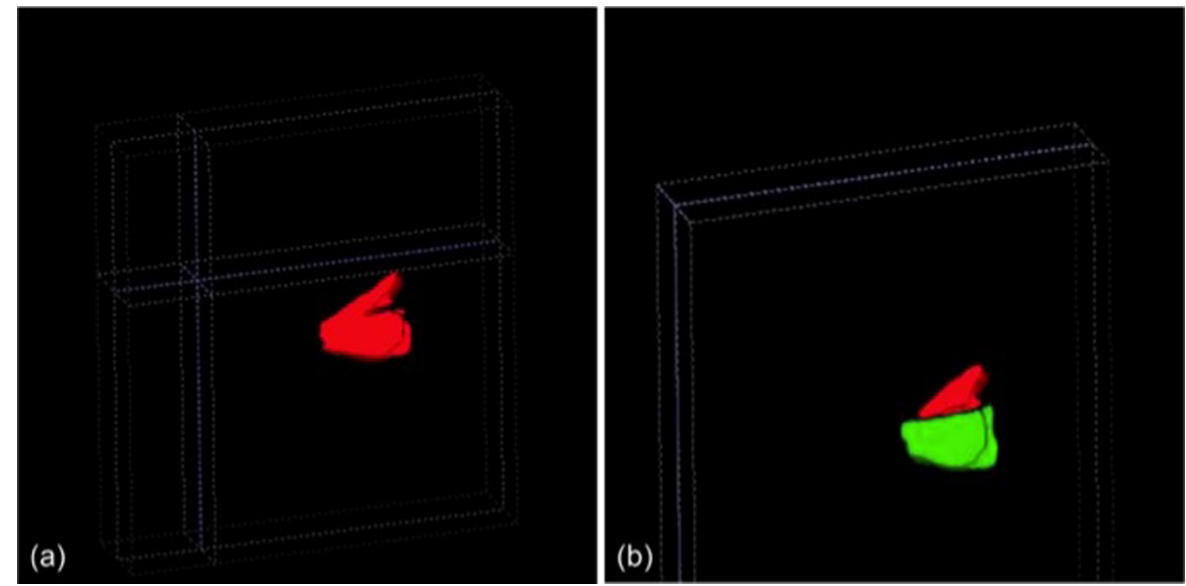

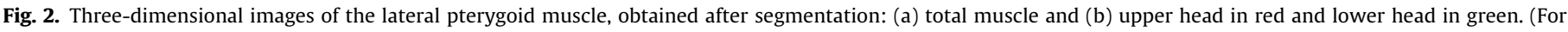
interpretation of the references to color in this figure legend, the reader is referred to the web version of this article.)
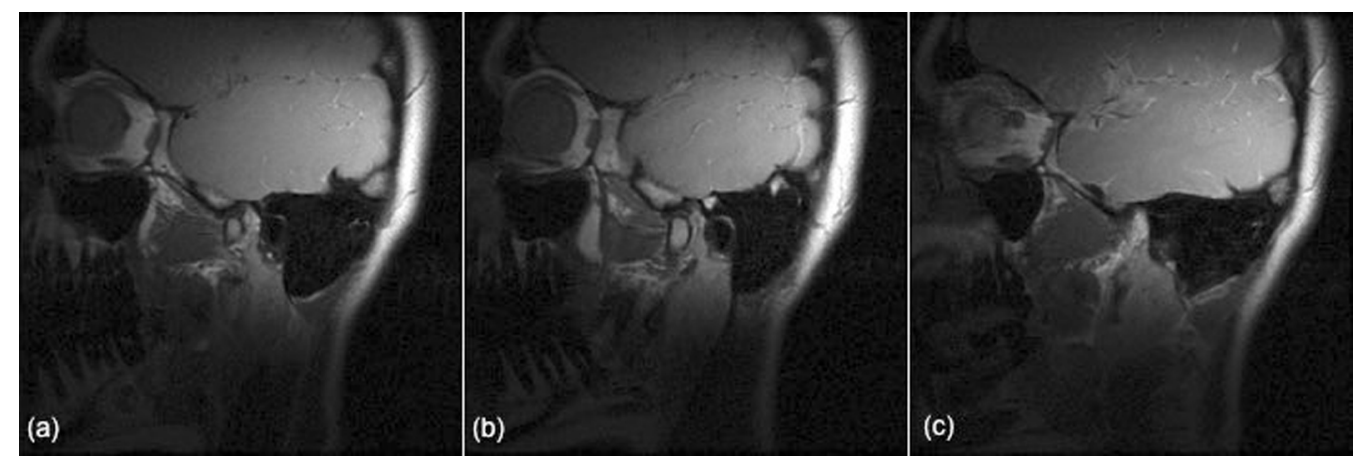

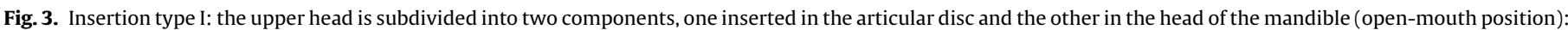
(a) lateral image, (b) central image and (c) medial image.

muscles, as well as their upper and lower heads (Fig. 2) (Yushkevich et al., 2006). This software allows for an active contour of anatomical structures and for the segmentation of regions delineated by the examiner (Costa et al., 2008b; Yushkevich et al., 2006). The process of segmentation correlates image points (voxels) to specific anatomical structures. In the current study, we selected the three consecutive slices with the most detail and sharpness for each TMJ (Fujita et al., 2001). Selected images had a $512 \times 512$ matrix with pixels and voxels measuring $0.29 \mathrm{~mm}$ (height) $\times 0.29 \mathrm{~mm}$ (width) $\times 3.00 \mathrm{~mm}$ (depth). The software generates volumetric data after 3D image reconstruction.

The closed- and open-mouth images were randomized, segmented and 3D reconstructed in a Sony Vaio i $7^{\circledR}$ S $13^{\prime \prime}$ SVS notebook
(Sony Corporation, China). The examiner could manipulate brightness, contrast and zoom utilizing the software tools to improve diagnosis. Fifteen days after the first stage of evaluation, the examiner repeated the procedure for 14 randomly selected patients, utilizing closed- and open-mouth images.

In addition to volumetric data, the examiner also registered the insertion pattern of the upper head of the LPM, using closed- and open-mouth images (Dergin et al., 2012; Imanimoghaddam et al., 2013; Mazza et al., 2009). Three insertion types were defined: type I (Fig. 3) - the upper head is subdivided into two components, one inserted in the articular disc and the other in the mandible head; type II (Fig. 4) - there is no subdivision of the upper head, but the muscle is inserted in both the articular disc and the mandible head;
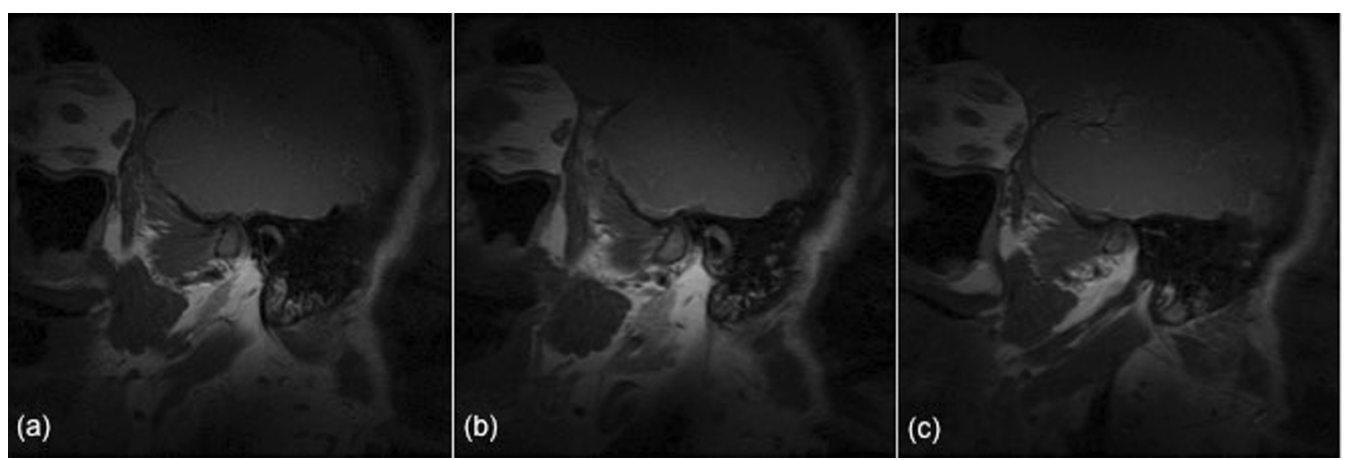

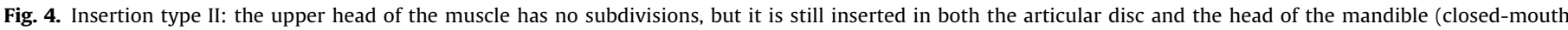
position): (a) lateral image, (b) central image and (c) medial image. 


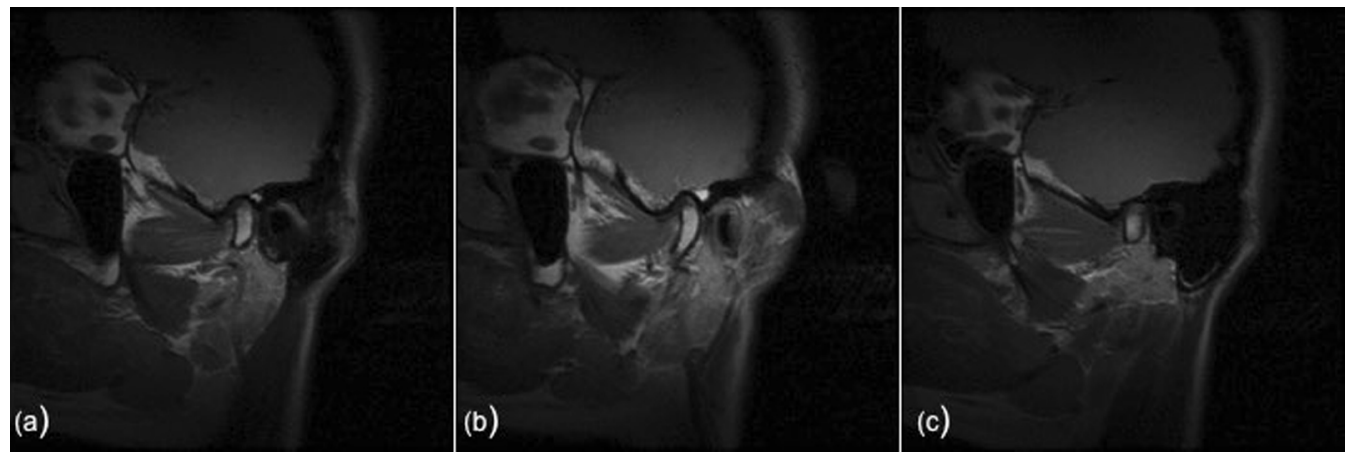

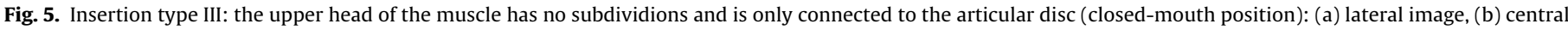
image and (c) medial image.

and type III, the muscle upper head, with no subdivisions, is inserted in the articular disc (Fig. 5). Three-dimensional images of all three different patterns were acquired as well (Fig. 6).

\subsection{Statistical analyses}

The reproducibility of volume estimates for the lateral pterygoid muscle was assessed through Lin's concordance correlation coefficient and Spearman's correlation. Comparisons of volumetric data from closed- and open-mouth images were performed using averages and the likelihood-ratio test. Co-variance effects such as side (right and left), gender, age group, type of insertion of the muscle upper head, articular disc morphology, presence/absence of effusion, and position of the articular disc (normal/anterior dislocation with or without reduction) were analyzed by linear regression
( $\alpha=5 \%$ ). Analyses were performed utilizing the $\mathrm{R}$ software, version 3.0.2 (The R Foundation for Statistical Computing, Vienna, Austria).

\section{Results}

The most prevalent type of insertion was characterized by a single upper head of the LPM adhering both to the disc and the mandible head (type II), accounting for $50 \%$ of insertions on the right side and $75 \%$ on the left. Most patients presented some morphological alteration to the right (54.2\%) and left (70.8\%) articular discs. The effusion signal varied between $20.8 \%$ and $29.2 \%$. The frequency of images compatible with disc dislocation, with or without reduction, was lower than $40 \%$ (Table 2 ).

Measurements were highly consistent and reproducible, as shown in Table 3: Spearman's coefficients ranged between 0.857
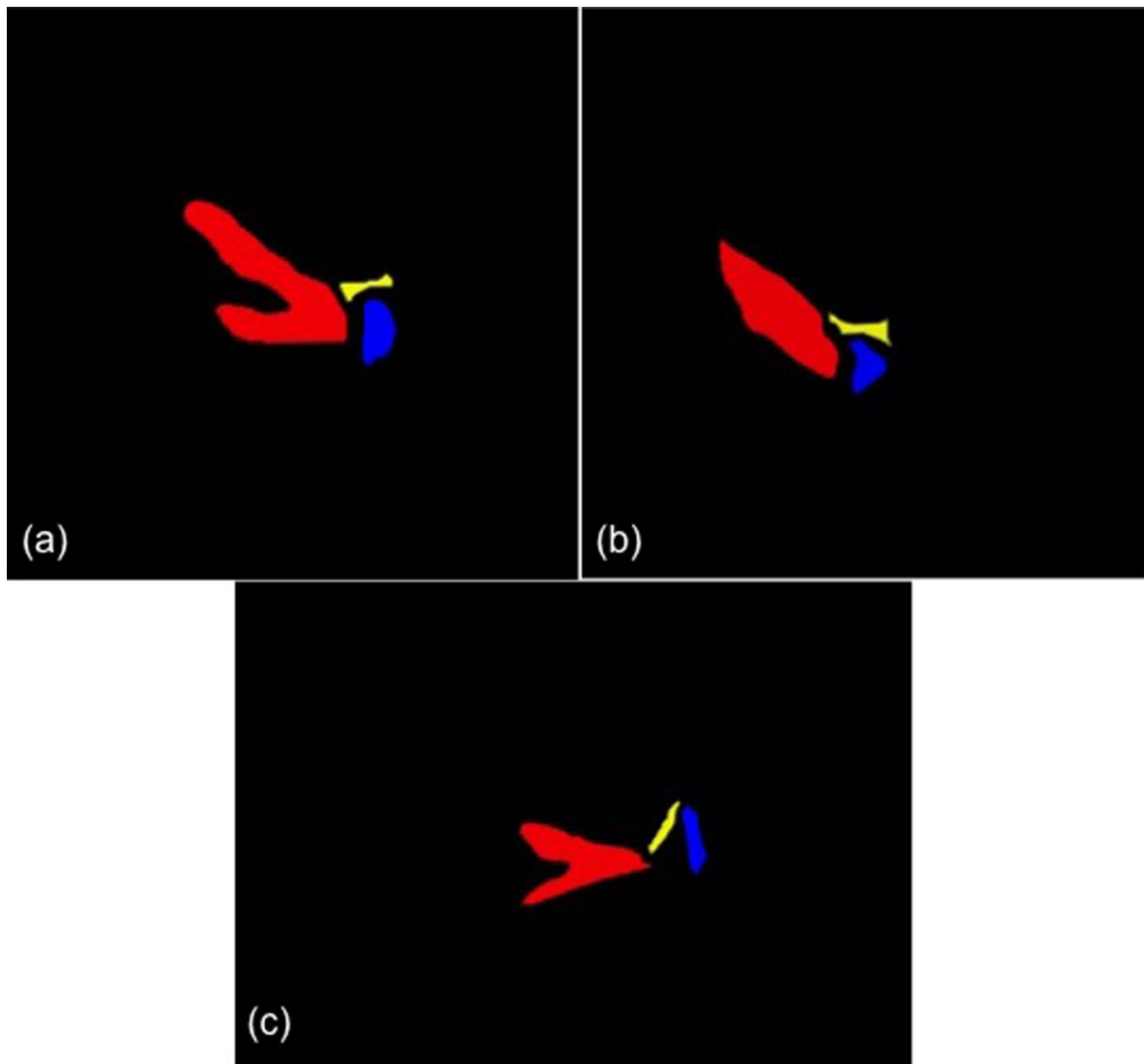

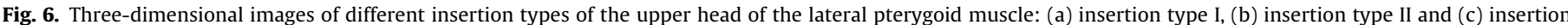

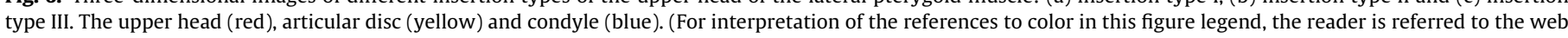
version of this article.) 
Table 2

Distribution of the sample according to type of insertion of the lateral pterygoid upper head, articular disc morphology, effusion signal, and articular disc displacement.

\begin{tabular}{|c|c|c|c|c|}
\hline \multirow[t]{3}{*}{ Characteristic } & \multicolumn{4}{|c|}{ Side } \\
\hline & \multicolumn{2}{|c|}{ Right } & \multicolumn{2}{|l|}{ Left } \\
\hline & $n$ & $\%$ & $n$ & $\%$ \\
\hline \multicolumn{5}{|l|}{ Insertion type } \\
\hline I & 1 & 4.2 & 3 & 12.5 \\
\hline II & 12 & 50.0 & 18 & 75.0 \\
\hline III & 11 & 45.8 & 3 & 12.5 \\
\hline \multicolumn{5}{|l|}{ Disc morphology } \\
\hline Normal & 11 & 45.8 & 7 & 29.2 \\
\hline Altered & 13 & 54.2 & 17 & 70.8 \\
\hline \multicolumn{5}{|l|}{ Effusion } \\
\hline Absent & 17 & 70.8 & 19 & 79.2 \\
\hline Present & 7 & 29.2 & 5 & 20.8 \\
\hline \multicolumn{5}{|l|}{ Disc displacement } \\
\hline Absent & 15 & 62.5 & 16 & 66.7 \\
\hline Without reduction & 7 & 29.2 & 7 & 29.2 \\
\hline With reduction & 2 & 8.3 & 1 & 4.2 \\
\hline Total & 24 & 100.0 & 24 & 100.0 \\
\hline
\end{tabular}

and 0.998, $p<0.0001$, and Lin's concordance correlation coefficient (CCC) for the two measurements ranged between 0.898 and 0.999 .

As evidenced by the standard deviation values shown in Table 4, muscle volumes varied considerably from the average, suggesting that median values may provide a more solid basis for analysis. Thus, the median volumes of the upper heads of the muscle on both sides and both mouth positions were lower than those from the lower head of the muscle. Additionally, muscle volumes were lower in the open-mouth compared to the closed-mouth position.
Table 5

Likelihood ratio test for comparisons between average muscle volumes in the openand closed-mouth positions.

\begin{tabular}{llc}
\hline & $\begin{array}{l}\text { Differences between averages for the } \\
\text { open- and closed-mouth positions }\end{array}$ & $p$-value \\
\hline Total & 622.0 & 0.0004 \\
Upper head & 109.5 & 0.5090 \\
Lower head & 501.5 & 0.0015
\end{tabular}

The likelihood ratio test validated this observation for total muscle volume and for the lower head of the muscle (Table 5).

To evaluate potential effects of side, gender, age group, type of insertion, disc morphology, effusion signal, and anterior displacement, we employed mixed models of linear regression, controlling for the variability of repeated measures on the right and left sides. According to the Shapiro-Wilks test, the residuals departed from normality $(p>0.05)$.

Type of insertion had a significant effect on total muscle volume in the closed-mouth position (Table 6). If we take the type II insertion as a reference for comparison, patients with type III insertion had significantly larger muscle volume $(p=0.0020)$. Similarly, patients with type III insertions had larger volumes than those with type I ( $p=0.0338)$.

When assessing muscle volume in the open-mouth position, we detected an effect of gender (Table 7). Total muscle volume was significantly larger in male compared to female patients $(p=0.0272)$.

Table 8 shows that, in the closed-mouth position, the volume of the upper head of the lateral pterygoid muscle was significantly larger among male patients $(p=0.0002)$.

Three co-variables significantly affected the volume of the upper head of the lateral pterygoid in the open-mouth position: gender, insertion type, and anterior articular disc displacement (Table 9). In

Table 3

Analysis of correlation and reproducibility.

\begin{tabular}{|c|c|c|c|c|c|c|c|}
\hline \multirow[t]{2}{*}{ Muscle/mouth position } & \multirow[t]{2}{*}{ Measure } & \multirow[t]{2}{*}{ Average $\left(\mathrm{mm}^{3}\right)$} & \multirow[t]{2}{*}{ SD } & \multirow[t]{2}{*}{ Spearman's correlation ${ }^{*}$} & \multicolumn{3}{|l|}{ Lin's } \\
\hline & & & & & $\mathrm{CCC}$ & CI 95\% & \\
\hline Total/closed & 1 & 4649.2 & 1325.6 & 0.9984 & 0.9994 & 0.9987 & 0.9997 \\
\hline \multirow{2}{*}{ Total/opened } & 1 & 5188.8 & 4394.1 & \multirow[b]{2}{*}{0.9850} & \multirow[b]{2}{*}{0.9993} & \multirow[b]{2}{*}{0.9986} & \multirow[b]{2}{*}{0.9997} \\
\hline & 2 & 5115.2 & 4456.9 & & & & \\
\hline \multirow{2}{*}{ Upper/closed } & 1 & 1598.7 & 431.1 & \multirow{2}{*}{0.9973} & \multirow{2}{*}{0.9973} & \multirow{2}{*}{0.9947} & \multirow[b]{2}{*}{0.9987} \\
\hline & 2 & 1582.4 & 443.8 & & & & \\
\hline \multirow{2}{*}{ Lower/closed } & 1 & 2953.0 & 1070.4 & \multirow[b]{2}{*}{0.8571} & \multirow[b]{2}{*}{0.8986} & \multirow[b]{2}{*}{0.7938} & \multirow[b]{2}{*}{0.9516} \\
\hline & 2 & 3015.7 & 1044.2 & & & & \\
\hline \multirow{2}{*}{ Upper/opened } & 1 & 2053.1 & 1917.2 & \multirow{2}{*}{0.9467} & \multirow{2}{*}{0.9983} & \multirow{2}{*}{0.9962} & \multirow{2}{*}{0.9992} \\
\hline & 2 & 2007.9 & 1913.7 & & & & \\
\hline \multirow{2}{*}{ Lower/opened } & 1 & 3068.9 & 2530.1 & \multirow{2}{*}{0.9836} & \multirow{2}{*}{0.9994} & \multirow{2}{*}{0.9987} & \multirow{2}{*}{0.9997} \\
\hline & 2 & 3039.7 & 2526.6 & & & & \\
\hline
\end{tabular}

${ }^{*} p<0.0001$ for all estimates.

Table 4

Total, upper head, and lower head volumes of pterygoid muscles.

\begin{tabular}{|c|c|c|c|c|c|c|c|}
\hline \multicolumn{8}{|l|}{ Volumes in $\mathrm{mm}^{3}$} \\
\hline Mouth position & Side & Muscle part & Min & Max & Med & Avg & SD \\
\hline \multirow{6}{*}{ Closed } & \multirow{3}{*}{ Right } & Upper & 693.2 & 5121.7 & 1787.6 & 2021.7 & 962.4 \\
\hline & & Lower & 1057.5 & $17,535.8$ & 3340.4 & 3964.5 & 3156.6 \\
\hline & & Total & 2187.5 & $23,030.7$ & 5053.0 & 6160.5 & 3984.3 \\
\hline & \multirow{3}{*}{ Left } & Upper & 558.6 & 3315.0 & 1809.4 & 1844.4 & 634.2 \\
\hline & & Lower & 1027.9 & 5605.1 & 3061.3 & 3140.2 & 1165.0 \\
\hline & & Total & 1663.8 & 7593.0 & 4938.6 & 4932.1 & 1604.6 \\
\hline \multirow{6}{*}{ Opened } & \multirow{3}{*}{ Right } & Upper & 745.6 & 6964.6 & 1435.3 & 1815.3 & 1211.0 \\
\hline & & Lower & 719.5 & $10,024.7$ & 2937.3 & 3164.5 & 1802.3 \\
\hline & & Total & 2003.1 & $17,215.0$ & 4429.9 & 5081.8 & 2906.3 \\
\hline & \multirow{3}{*}{ Left } & Upper & 818.2 & $11,221.2$ & 1755.9 & 2546.4 & 2581.5 \\
\hline & & Lower & 1492.0 & $15,051.7$ & 2762.3 & 3580.3 & 2991.7 \\
\hline & & Total & 2262.8 & $26,335.9$ & 4657.1 & 6230.9 & 5595.3 \\
\hline
\end{tabular}


Table 6

Linear regression analysis correlating patient variables and the volume of the lateral pterygoid muscle in the closed-mouth position.

\begin{tabular}{|c|c|c|c|c|c|c|c|}
\hline \multirow[t]{3}{*}{ Variable } & \multirow[t]{3}{*}{ Category } & \multicolumn{6}{|c|}{ Total Volume } \\
\hline & & \multicolumn{3}{|c|}{ Simple linear mixed model } & \multicolumn{3}{|c|}{ Multiple linear mixed model } \\
\hline & & Avg & SE & $p^{\mathrm{a}}$-value & Beta & SE & $p^{\mathrm{b}}$-value \\
\hline Intercept & - & - & - & & 4845.6 & 324.2 & $<0.0001$ \\
\hline \multirow{2}{*}{ Side } & Right & 5276.7 & 341.1 & 0.0898 & & & \\
\hline & Left & 4932.1 & 338.7 & & & & \\
\hline \multirow{2}{*}{ Gender } & Female & 4909.6 & 407.0 & 0.4105 & & & \\
\hline & Male & 5455.3 & 560.4 & & & & \\
\hline \multirow{3}{*}{ Age group } & $\leq 39$ & 5423.3 & 413.7 & 0.1958 & & & \\
\hline & $\geq 40$ & 4587.8 & 518.6 & & & & \\
\hline & I & 4898.9 & 497.9 & 0.0070 & 53.3 & 450.4 & 0.9060 \\
\hline \multirow[t]{2}{*}{ Insertion type } & II & 4845.6 & 324.3 & & c & & \\
\hline & III & 5873.1 & 392.2 & & 1027.5 & 332.9 & 0.0020 \\
\hline \multirow{2}{*}{ Format } & Normal & 5283.3 & 415.9 & 0.4670 & & & \\
\hline & Altered & 4977.4 & 370.1 & & & & \\
\hline \multirow{2}{*}{ Effusion } & No & 4916.4 & 347.5 & 0.0998 & & & \\
\hline & Yes & 5605.8 & 448.6 & & & & \\
\hline \multirow{2}{*}{ Displacement } & No & 5039.6 & 359.7 & 0.6827 & & & \\
\hline & Yes & 5197.5 & 409.8 & & & & \\
\hline
\end{tabular}

a Refers to the likelihood ratio test of differences among averages.

b Refers to the $t$-test comparing the beta coefficient to zero.

c Reference category used for the comparisons.

the simple linear model, differences were not significant, although they obtained a $p$-value that was close to 0.05 . In the multiple linear model, in fact, male patients displayed a significantly larger volume of the upper head of the lateral pterygoid compared to females $(p=0.0288)$. Patients with type I insertion had significantly larger volumes than type III insertion patients $(p=0.0130)$, whereas there was only a tendency for type II insertion patients to have larger volumes than type III insertion patients $(p=0.0684)$. Patients with any degree of articular displacement had larger upper head volumes than those without displacement $(p=0.0358)$. This finding could result from a confounding or associative effect of displacementgender, displacement-insertion and/or gender-insertion. However, when we evaluated the joint effect of these three co-variables, all of them displayed a significant effect.

Table 10 shows that the lower head muscle volume in the closedmouth position was significantly larger in patients with type III insertion in comparison with type II $(p=0.0033)$. In the open-mouth position (Table 11), the lower head volume was larger on the right side relative to the left $(p=0.0412)$.

\section{Discussion}

In previous studies, authors have diverged about the number of insertion patterns of the upper head of the LPM. While some authors (Omami and Lurie, 2012; Taskaya-Yilmaz et al., 2005) report two types of insertion - a single insertion in the articular disc, or simultaneous insertion in the disc and in the head of the mandible - others claim there are three types of insertion (Dergin et al., 2012; Imanimoghaddam et al., 2013; Mazza et al., 2009). After detailed evaluation of the MRI files, we indeed find that three types of insertion can be described for the upper head of the muscle (Fig. 2) (Imanimoghaddam et al., 2013; Mazza et al., 2009). Based on the interpretation of parasagittal MR images of the LPM in the open- and closed-mouth positions, we observed that type II represented the most frequent insertions, whereas type I represented the least frequent (Table 2). Other studies reported similarly higher frequencies for type II insertions (Dergin et al., 2012). Besides, some authors (Imanimoghaddam et al., 2013) reported the highest prevalence for type I (63.8\%) and the lowest for type III (12.5\%) insertions.

Table 7

Linear regression analysis correlating patient variables and the volume of the lateral pterygoid muscle in the open-mouth position.

\begin{tabular}{|c|c|c|c|c|c|c|c|}
\hline \multirow[t]{3}{*}{ Variable } & \multirow[t]{3}{*}{ Category } & \multicolumn{6}{|c|}{ Total volume } \\
\hline & & \multicolumn{3}{|c|}{ Simple linear mixed model } & \multicolumn{3}{|c|}{ Multiple linear mixed model } \\
\hline & & Avg & SE & $p^{\mathrm{a}}$-value & Beta & SE & $p^{\mathrm{b}}$-value \\
\hline Intercept & - & - & - & & 4033.4 & 307.5 & $<0.0001$ \\
\hline \multirow{2}{*}{ Side } & Right & 4530.3 & 273.3 & 0.6984 & & & \\
\hline & Left & 4491.4 & 274.2 & & & & \\
\hline \multirow{2}{*}{ Gender } & Female & 4175.2 & 305.6 & 0.0500 & c & & \\
\hline & Male & 5232.2 & 446.8 & & 1173.5 & 531.2 & 0.0272 \\
\hline \multirow{3}{*}{ Age group } & $\leq 39$ & 4725.2 & 350.1 & 0.3222 & & & \\
\hline & $\geq 40$ & 4203.7 & 420.3 & & & & \\
\hline & I & 4502.8 & 346.5 & 0.9866 & & & \\
\hline \multirow[t]{2}{*}{ Insertion type } & II & 4502.7 & 280.4 & & & & \\
\hline & III & 4531.8 & 300.6 & & & & \\
\hline \multirow{2}{*}{ Format } & Normal & 4558.8 & 309.3 & 0.7513 & & & \\
\hline & Altered & 4482.2 & 285.8 & & & & \\
\hline \multirow{2}{*}{ Effusion } & No & 4523.8 & 274.6 & 0.8110 & & & \\
\hline & Yes & 4470.5 & 320.6 & & & & \\
\hline \multirow{2}{*}{ Displacement } & No & 4421.8 & 273.9 & 0.1156 & c & & \\
\hline & Yes & 4724.6 & 300.1 & & 353.4 & 192.1 & 0.0659 \\
\hline
\end{tabular}

a Refers to the likelihood ratio test of differences among averages.

b Refers to the $t$-test comparing the beta coefficient to zero.

c Reference category used for comparisons. 
Table 8

Linear regression analysis correlating patient variables and the volume of the upper head of the lateral pterygoid muscle in the closed-mouth position.

\begin{tabular}{|c|c|c|c|c|c|c|c|}
\hline \multirow[t]{3}{*}{ Variable } & \multirow[t]{3}{*}{ Category } & \multicolumn{6}{|c|}{ Volume of the upper head of the lateral pterygoid muscle } \\
\hline & & \multicolumn{3}{|c|}{ Simple linear mixed model } & \multicolumn{3}{|c|}{ Multiple linear mixed model } \\
\hline & & Avg & SE & $p^{\mathrm{a}}$-value & Beta & SE & $p^{\mathrm{b}}$-value \\
\hline Intercept & - & - & - & & 1648.8 & 130.9 & $<0.0001$ \\
\hline \multirow[b]{2}{*}{ Side } & Right & 2021.7 & 169.9 & 0.4233 & & & \\
\hline & Left & 1844.4 & 169.9 & & & & \\
\hline \multirow{2}{*}{ Gender } & Female & 1648.8 & 130.9 & 0.0005 & c & & \\
\hline & Male & 2466.1 & 179.2 & & 817.4 & 221.9 & 0.0002 \\
\hline \multirow{3}{*}{ Age group } & $\leq 39$ & 1877.5 & 166.0 & 0.5771 & & & \\
\hline & $\geq 40$ & 2019.4 & 207.1 & & & & \\
\hline & I & 2151.3 & 395.6 & 0.1563 & & & \\
\hline \multirow[t]{2}{*}{ Insertion type } & II & 1769.7 & 152.8 & & & & \\
\hline & III & 2268.8 & 234.3 & & & & \\
\hline \multirow{2}{*}{ Format } & Normal & 1919.3 & 203.6 & 0.9254 & & & \\
\hline & Altered & 1941.9 & 164.3 & & & & \\
\hline \multirow{2}{*}{ Effusion } & No & 1935.8 & 149.3 & 0.9731 & & & \\
\hline & Yes & 1925.3 & 247.0 & & & & \\
\hline \multirow{2}{*}{ Displacement } & No & 2017.0 & 159.0 & 0.3633 & & & \\
\hline & Yes & 1790.0 & 205.8 & & & & \\
\hline
\end{tabular}

a Refers to the likelihood ratio test of differences among averages.

b Refers to the $t$-test comparing the beta coefficient to zero.

c Reference category used for comparisons.

Despite studies reporting only two types of insertion (Omami and Lurie, 2012; Taskaya-Yilmaz et al., 2005), in one of them (Omami and Lurie, 2012), 62.5\% of patients had the upper head of the muscle connected to both the disc and the head of the mandible, corroborating our findings. In the other study (Taskaya-Yilmaz et al., 2005), the authors reported no type I insertions, possibly resulting from differences in methodology. These authors only evaluated MR images in the closed-mouth position, meaning that they were not able to visualize the entire upper head of the muscle, which can only be seen with the contraction in the open-mouth position (Mazza et al., 2009).

A clear association between type of insertion and anterior articular disc displacement has yet to be unveiled (Dergin et al., 2012; Omami and Lurie, 2012; Taskaya-Yilmaz et al., 2005). However, upper head insertion in the articular disc alone may render an individual more susceptible to anterior articular disc displacement. Thus, clearly defining insertion patterns has prognostic relevance (Taskaya-Yilmaz et al., 2005). The lateral pterygoid muscle has been implicated in anterior articular disc displacement and, as a consequence, in TMD (Balcioglu et al., 2009; Barriere et al., 2009; Costa et al., 2008a; D'Ippolito et al., 2010; Dergin et al., 2012; Omami and Lurie, 2012; Taskaya-Yilmaz et al., 2005). Anterior displacement represents the most frequent sign of TMD (Murray et al., 2007). In cases of displacement with reduction, the upper head of the lateral pterygoid muscle may be normal or hypertrophied (D'Ippolito et al., 2010; Taskaya-Yilmaz et al., 2005). Moreover, in cases of displacement with no reduction, the upper head may have undergone atrophy (Taskaya-Yilmaz et al., 2005) [26].

Interestingly, muscle volume on both sides was statistically smaller in the open-mouth compared to the closed-mouth position (Table 4). This difference held true for both total muscle volume and lower head (Table 5), reflecting the smaller contribution of the upper head to the volume of the LPM. Presumably, volumetric alterations in the different mouth positions result from the functions of the pterygoid muscle heads. The lower head lowers and protrudes the mandible, whereas the upper head raises the mandible and/or

Table 9

Linear regression analysis correlating patient variables and the volume of the upper head of the lateral pterygoid muscle in the open-mouth position.

\begin{tabular}{|c|c|c|c|c|c|c|c|}
\hline \multirow[t]{3}{*}{ Variable } & \multirow[t]{3}{*}{ Category } & \multicolumn{6}{|c|}{ Volume of the upper head of the lateral pterygoid muscle } \\
\hline & & \multicolumn{3}{|c|}{ Simple linear mixed model } & \multicolumn{3}{|c|}{ Multiple linear mixed model } \\
\hline & & Avg & SE & $p^{a}$-value & Beta & SE & $p^{\mathrm{b}}$-value \\
\hline Intercept & - & - & - & & 1774.1 & 353.6 & $<0.0001$ \\
\hline \multirow{2}{*}{ Side } & Right & 1815.3 & 250.8 & 0.1214 & & & \\
\hline & Left & 1991.6 & 252.9 & & & & \\
\hline \multirow{2}{*}{ Gender } & Female & 1589.1 & 284.7 & 0.0661 & c & & \\
\hline & Male & 2467.4 & 390.4 & & 990.6 & 453.1 & 0.0288 \\
\hline \multirow{3}{*}{ Age group } & $\leq 39$ & 1773.0 & 327.1 & 0.5563 & & & \\
\hline & $\geq 40$ & 2054.4 & 373.2 & & & & \\
\hline & I & 2266.9 & 329.0 & 0.0655 & c & & \\
\hline \multirow{2}{*}{ Insertion type } & II & 1962.5 & 251.1 & & -273.8 & 257.9 & 0.2882 \\
\hline & III & 1655.9 & 276.9 & & -646.6 & 260.2 & 0.0130 \\
\hline \multirow{2}{*}{ Format } & Normal & 1785.0 & 295.6 & 0.5463 & & & \\
\hline & Altered & 1973.5 & 273.8 & & & & \\
\hline \multirow{2}{*}{ Effusion } & No & 1931.5 & 247.7 & 0.4953 & & & \\
\hline & Yes & 1762.6 & 311.7 & & & & \\
\hline \multirow{2}{*}{ Displacement } & No & 1783.6 & 245.5 & 0.1199 & c & & \\
\hline & Yes & 2124.2 & 278.1 & & 428.8 & 204.3 & 0.0358 \\
\hline
\end{tabular}

a Refers to the likelihood ratio test of differences among averages.

b Refers to the $t$-test comparing the beta coefficient to zero.

c Reference category used for comparisons. 
Table 10

Linear regression analysis correlating patient variables and the volume of the lower head of the lateral pterygoid muscle in the closed-mouth position.

\begin{tabular}{|c|c|c|c|c|c|c|c|}
\hline \multirow[t]{3}{*}{ Variable } & \multirow[t]{3}{*}{ Category } & \multicolumn{6}{|c|}{ Volume of the lower head of the lateral pterygoid muscle } \\
\hline & & \multicolumn{3}{|c|}{ Simple linear mixed model } & \multicolumn{3}{|c|}{ Multiple linear mixed model } \\
\hline & & Avg & SE & $p^{\mathrm{a}}$-value & Beta & SE & $p^{\mathrm{b}}$-value \\
\hline Intercept & - & - & - & & 2935.6 & 210.7 & $<0.0001$ \\
\hline \multirow{2}{*}{ Side } & Right & 3302.5 & 244.1 & 0.4705 & & & \\
\hline & Left & 3140.2 & 240.4 & & & & \\
\hline \multirow{2}{*}{ Gender } & Female & 3204.8 & 270.3 & 0.9268 & & & \\
\hline & Male & 3241.5 & 374.9 & & & & \\
\hline \multirow{3}{*}{ Age group } & $\leq 39$ & 3450.8 & 268.6 & 0.1538 & & & \\
\hline & $\geq 40$ & 2847.8 & 339.1 & & & & \\
\hline & I & 3415.3 & 472.8 & 0.0192 & 479.7 & 493.6 & 0.3311 \\
\hline \multirow[t]{2}{*}{ Insertion type } & II & 2935.6 & 210.7 & & c & & \\
\hline & III & 3951.1 & 313.3 & & 1015.5 & 345.0 & 0.0033 \\
\hline \multirow{2}{*}{ Format } & Normal & 3197.4 & 308.1 & 0.9002 & & & \\
\hline & Altered & 3231.6 & 259.4 & & & & \\
\hline \multirow{2}{*}{ Effusion } & No & 3076.9 & 241.2 & 0.1768 & & & \\
\hline & Yes & 3606.5 & 355.3 & & & & \\
\hline \multirow{2}{*}{ Displacement } & No & 3141.1 & 254.9 & 0.5802 & & & \\
\hline & Yes & 3345.3 & 309.8 & & & & \\
\hline
\end{tabular}

a Refers to the likelihood ratio test of differences among averages.

b Refers to the $t$-test comparing the beta coefficient to zero.

c Reference category used for comparisons.

stabilizes the TMJ [24]. One study (Goto et al., 2002) also observed a significant reduction $(-6.7 \%)$ in the volume of the LPM as the mandible opened.

In general, type III insertions - upper head directly inserted in the disc - were associated with larger muscle volumes (Tables 6, 7, 8, 10 and 11). A reduction in muscle upper head volume in the open-mouth position (Table 9) constitutes the sole exception to this pattern, and may indicate a reduction in the function of this component. Previous work supports the idea that type III insertions are more frequently associated with disc displacement without reduction, which would reduce muscle function and, consequently, volume (Taskaya-Yilmaz et al., 2005). Type III insertions could correlate with worse prognosis, because of a greater susceptibility to displacement without reduction (Mazza et al., 2009). Nevertheless, if we take into account the morpho-functional division of the lateral pterygoid muscle in upper and lower heads (Omami and Lurie, 2012), we should not expect similar volumetric alterations for both components, and the volume of the lower head should be larger.
In this sense, and in agreement with our results, the lower head contributes substantially to total lateral pterygoid volume, and has fewer implications for TMD.

We evaluated this sign of effusion because it correlates well with anterior articular disc displacement with and without reduction (Almasan et al., 2013) and also represents a biomarker for TMD-associated cephalea (Costa et al., 2008a). Presumably, the relatively low frequency of anterior displacements observed (17 joints; $35.4 \%$ ) explains the low number of joints with effusion (Table 2). Moreover, more than half of the joints displayed some degree of alteration to articular disc morphology, $54.2 \%$ of the right side joints and $70.8 \%$ of the left side joints. Thus, even though more than $60 \%$ of joints had normally positioned discs, morphological alterations occurred with relative high frequency and should be considered clinically. Such alterations suggest the existence of TMJ pathologies and may progressively lead to anterior disc displacement (Amaral Rde et al., 2013; Fujita et al., 2001). In line with our own work, a previous study found a high frequency of

Table 11

Linear regression analysis correlating patient variables and the volume of the lower head of the lateral pterygoid muscle in the open-mouth position.

\begin{tabular}{|c|c|c|c|c|c|c|c|}
\hline \multirow[t]{3}{*}{ Variable } & \multirow[t]{3}{*}{ Category } & \multicolumn{6}{|c|}{ Volume of the lower head of the lateral pterygoid muscle } \\
\hline & & \multicolumn{3}{|c|}{ Simple linear mixed model } & \multicolumn{3}{|c|}{ Multiple linear mixed model } \\
\hline & & Avg & SE & $p^{\mathrm{a}}$-value & Beta & SE & $p^{\mathrm{b}}$-value \\
\hline Intercept & - & - & - & & 2612.5 & 236.96 & $<0.0001$ \\
\hline \multirow{2}{*}{ Side } & Right & 2852.7 & 207.7 & 0.0490 & c & & \\
\hline & Left & 2653.3 & 208.6 & & -199.55 & 97.71 & 0.0412 \\
\hline \multirow{2}{*}{ Gender } & Female & 2520.3 & 229.8 & 0.0638 & c & & \\
\hline & Male & 3267.6 & 335.6 & & 754.87 & 411.64 & 0.0667 \\
\hline \multirow{3}{*}{ Age group } & $\leq 39$ & 2889.7 & 262.6 & 0.4140 & & & \\
\hline & $\geq 40$ & 2569.0 & 314.9 & & & & \\
\hline & I & 2487.8 & 291.2 & 0.2175 & & & \\
\hline \multirow[t]{2}{*}{ Insertion type } & II & 2715.3 & 216.6 & & & & \\
\hline & III & 2914.4 & 239.4 & & & & \\
\hline \multirow{2}{*}{ Format } & Normal & 2897.7 & 251.3 & 0.3562 & & & \\
\hline & Altered & 2670.1 & 224.7 & & & & \\
\hline \multirow{2}{*}{ Effusion } & No & 2772.3 & 208.0 & 0.7881 & & & \\
\hline & Yes & 2710.8 & 266.3 & & & & \\
\hline \multirow{2}{*}{ Displacement } & No & 2731.5 & 208.4 & 0.6468 & & & \\
\hline & Yes & 2822.6 & 245.7 & & & & \\
\hline
\end{tabular}

\footnotetext{
a Refers to the likelihood ratio test of differences among averages.

b Refers to the $t$-test comparing the beta coefficient to zero.
}

c Reference category used for comparisons. 
biplanar alterations on the right (55\%) and left (45\%) sides in cases of normal disc positioning (Amaral Rde et al., 2013). The morphological differences between the biconcave normal disc and the biplanar altered disc are subtle and may explain why disc positioning remains normal in spite of format changes (Amaral Rde et al., 2013).

Linear regression analyses did not provide any evidence of effects that effusion and altered disc format might have on muscle volume (Tables 6-11). Previous work suggested that disc format alterations might occur in the initial phases of functional changes to the TMJ (Taskaya-Yilmaz and Ogutcen-Toller, 2001). Instead, articular effusion is significantly associated with displacements with or without reduction. One research (Almasan et al., 2013) have suggested that disc displacement without reduction, as a chronic alteration, could induce changes in the shape of the mandibular head and in its association with the articular fossa, leading to the accumulation of fluid (i.e., effusion).

Nevertheless, anterior articular disc displacement seems to affect total and upper head muscle volume in the open-mouth position (Tables 7 and 9). Upper head muscle volume in the open-mouth position was significantly larger in joints with disc displacement $(p=0.0358)$. D'Ippolito et al. (2010) diagnosed disc displacement in $20.4 \%$ of their patients and, although they did not measure LPM, suggested that TMD could cause changes in this muscle's thickness. According to these authors, the increased muscle thickness could be associated with anterior disc displacement and articular hypermobility. It could be further inferred that the increase in thickness should be associated with displacement with reduction, because displacement without reduction has been associated with muscle atrophy (Taskaya-Yilmaz et al., 2005). In a population of 46 patients ranging between 14 and 69 years of age, nine exhibited muscle hypoplasia, atrophy and/or fatty substitution of the LPM along with TMD (Schellhas, 1989). One patient with severe TMD displayed atrophy of the entire set of muscles of mastication (Schellhas, 1989).

Some authors performed visual qualitative analyses of the LPM in patients with or without TMD (D'Ippolito et al., 2010). However, no studies have attempted to use 3D images to quantify entire muscle, lower and upper head volume and independently associate these measurements with signs of TMD. Despite the division of the lateral pterygoid into two components with distinct (albeit reciprocal) functions, the existing literature does not treat these components as separate muscles (Murray et al., 2007; Omami and Lurie, 2012). According to some authors(Dergin et al., 2012), the LPM functions as a single motor unit, in which the upper and lower heads become active during mouth movements, with no correlation according to insertion type, presence or absence of displacement, disc or joint degeneration.

In the current study, gender affected muscle volume. In the open-mouth position, male patients had significantly larger total volumes (Table 7). Furthermore, the smaller upper head component was significantly larger in male patients in both mouth positions (Tables 8 and 9). This finding may reflect the general trend of men having larger muscles than women (Benington et al., 1999).

Distinct hypotheses attempt to associate functional alterations in the lateral pterygoid and TMD, including muscular hyperactivity, hypoactivity and poor coordination between muscle components that could lead to disc displacement (Costa et al., 2014; Hoglund and Scott, 2012). Anterior articular disc displacement affects the volume of the upper head of the lateral pterygoid (Table 9). The indication for physiotherapy should take into account not only TMD symptoms, but also the volumes of the muscles of mastication (Hoglund and Scott, 2012).

In conclusion, the total and lower head muscle volumes on both sides were significantly smaller in the open-compared to the closed-mouth position. Gender affected muscle volume, especially that of the upper head component. Furthermore, insertion type also seems to affect volume.

\section{Appendix A. Supplementary data}

Supplementary data associated with this article can be found, in the online version, at http://dx.doi.org/10.1016/j.aanat.2016.05. 007.

\section{References}

Almasan, O.C., Hedesiu, M., Baciut, G., Leucuta, D.C., Baciut, M., 2013. Disk and joint morphology variations on coronal and sagittal MRI in temporomandibular joint disorders. Clin. Oral Investig. 17 (4), 1243-1250.

Amaral Rde, O., Damasceno, N.N., de Souza, L.A., Devito, K.L., 2013. Magnetic resonance images of patients with temporomandibular disorders: prevalence and correlation between disk morphology and displacement. Eur. J. Radiol. 82 (6), 990-994.

Balcioglu, H.A., Uyanikgil, Y., Yuruker, S., Tuna, H.S., Karacayli, U., 2009. Volumetric assessment of lateral pterygoid muscle in unilateral chewing: a stereologic study. J. Craniofac. Surg. 20 (5), 1364-1366.

Barriere, P., Lutz, J.C., Zamanian, A., Wilk, A., Rhiem, S., Veillon, F., Kahn, J.L., 2009 MRI evidence of lateral pterygoid muscle palpation. Int. J. Oral Maxillofac. Surg. 38 (10), 1094-1095.

Benington, P.C., Gardener, J.E., Hunt, N.P., 1999. Masseter muscle volume measured using ultrasonography and its relationship with facial morphology. Eur. J. Orthod. 21 (6), 659-670.

Costa, A.L., D’Abreu, A., Cendes, F., 2008a. Temporomandibular joint internal derangement: association with headache, joint effusion, bruxism, and joint pain. J. Contemp. Dent. Pract. 9 (6), 9-16.

Costa, A.L., Yasuda, C.L., Appenzeller, S., Lopes, S.L., Cendes, F., 2008b. Comparison of conventional MRI and 3D reconstruction model for evaluation of temporomandibular joint. Surg. Radiol. Anat. 30 (8), 663-667.

Costa, A.L., Yasuda, C.L., Franca Jr., M., de Freitas, C.F., Tedeschi, H., de Oliveira, E. Cendes, F., 2014. Temporomandibular dysfunction post-craniotomy: evaluation between pre- and post-operative status. J. Craniomaxillofac. Surg. 42 (7), $1475-1479$.

D’Ippolito, S.M., Borri Wolosker, A.M., D’Ippolito, G., Herbert de Souza, B., FenyoPereira, M., 2010. Evaluation of the lateral pterygoid muscle using magnetic resonance imaging. Dentomaxillofac. Radiol. 39 (8), 494-500.

Dergin, G., Kilic, C., Gozneli, R., Yildirim, D., Garip, H., Moroglu, S., 2012. Evaluating the correlation between the lateral pterygoid muscle attachment type and internal derangement of the temporomandibular joint with an emphasis on MR imaging findings. J. Craniomaxillofac. Surg. 40 (5), 459-463.

Dworkin, S.F., 2010. Research diagnostic criteria for temporomandibular disorders: current status \& future relevance. J. Oral Rehabil. 37 (10), 734-743.

Dworkin, S.F., LeResche, L., 1992. Research diagnostic criteria for temporomandibular disorders: review, criteria, examinations and specifications, critique. J. Craniomandib. Disord. 6 (4), 301-355.

Farrugia, M.E., Bydder, G.M., Francis, J.M., Robson, M.D., 2007. Magnetic resonance imaging of facial muscles. Clin. Radiol. 62 (11), 1078-1086.

Fujita, S., Iizuka, T., Dauber, W., 2001. Variation of heads of lateral pterygoid muscle and morphology of articular disc of human temporomandibular joint - anatomical and histological analysis. J. Oral Rehabil. 28 (6), 560-571.

Goto, T.K., Tokumori, K., Nakamura, Y., Yahagi, M., Yuasa, K., Okamura, K., Kanda, S., 2002. Volume changes in human masticatory muscles between jaw closing and opening. J. Dent. Res. 81 (6), 428-432.

Hoglund, L.T., Scott, B.W., 2012. Automobilization intervention and exercise for temporomandibular joint open lock. J. Man. Manip. Ther. 20 (4), 182-191.

Imanimoghaddam, M., Madani, A.S., Hashemi, E.M., 2013. The evaluation of lateral pterygoid muscle pathologic changes and insertion patterns in temporomandibular joints with or without disc displacement using magnetic resonance imaging. Int. J. Oral Maxillofac. Surg. 42 (9), 1116-1120.

Lamey, P.J., Burnett, C.A., Fartash, L., Clifford, T.J., McGovern, J.M., 2001. Migraine and masticatory muscle volume, bite force, and craniofacial morphology. Headache 41 (1), 49-56

Lopes, S.L., Costa, A.L., Cruz, A.D., Li, L.M., de Almeida, S.M., 2012. Clinical and MRI investigation of temporomandibular joint in major depressed patients. Dentomaxillofac. Radiol. 41 (4), 316-322.

Mazza, D., Marini, M., Impara, L., Cassetta, M., Scarpato, P., Barchetti, F., Di Paolo, C., 2009. Anatomic examination of the upper head of the lateral pterygoid muscle using magnetic resonance imaging and clinical data. J. Craniofac. Surg. 20 (5), 1508-1511.

Murray, G.M., Bhutada, M., Peck, C.C., Phanachet, I., Sae-Lee, D., Whittle, T., 2007. The human lateral pterygoid muscle. Arch. Oral Biol. 52 (4), 377-380.

Ng, H.P., Foong, K.W., Ong, S.H., Goh, P.S., Huang, S., Liu, J., Nowinski, W.L., 2009. Quantitative analysis of human masticatory muscles using magnetic resonance imaging. Dentomaxillofac. Radiol. 38 (4), 224-231.

Omami, G., Lurie, A., 2012. Magnetic resonance imaging evaluation of discal attachment of superior head of lateral pterygoid muscle in individuals with symptomatic temporomandibular joint. Oral Surg. Oral Med. Oral Pathol. Oral Radiol. 114 (5), 650-657. 
Schellhas, K.P., 1989. MR imaging of muscles of mastication. Am. J. Roentgenol. 153 (4), 847-855.

Taskaya-Yilmaz, N., Ceylan, G., Incesu, L., Muglali, M., 2005. A possible etiology of the internal derangement of the temporomandibular joint based on the MRI observations of the lateral pterygoid muscle. Surg. Radiol. Anat. 27 (1), $19-24$.

Taskaya-Yilmaz, N., Ogutcen-Toller, M., 2001. Magnetic resonance imaging evaluation of temporomandibular joint disc deformities in relation to type of disc displacement. J. Oral Maxillofac. Surg. 59 (8), 860-865, discussion 865-866.

Tomas, X., Pomes, J., Berenguer, J., Quinto, L., Nicolau, C., Mercader, J.M., Castro, V., 2006. Mr imaging of temporomandibular joint dysfunction: a pictorial review. Radiographics 26 (3), 765-781.

Yushkevich, P.A., Piven, J., Hazlett, H.C., Smith, R.G., Ho, S., Gee, J.C., Gerig, G., 2006 User-guided 3D active contour segmentation of anatomical structures: significantly improved efficiency and reliability. Neuroimage 31 (3), 1116-1128. 